\title{
COVID-19: Is it time to revisit the research on calcium channel drug targets?
}

$\begin{array}{ll}\text { Authors: } & \text { Muthuswamy Balasubramanyam } \\ & \begin{array}{l}\text { Dean of Research and Senior Scientist, Madras Diabetes Research Foundation, } \\ \text { Chennai, India } \\ \text { *Correspondence to baluglobaldiab@gmail.com }\end{array} \\ & \text { Dr Balasubramanyam has declared no conflicts of interest. } \\ \text { Disclosure: } & \text { O7.05.20 } \\ \text { Received: } & \text { 26.05.20 } \\ \text { Accepted: } & \text { (Angiotensin converting enzyme inhibitors (ACEi), angiotensin receptor blockers } \\ \text { Keywords: } & \text { blockers (CCB), virus replication, voltage gated calcium channels (VGCC). } \\ \text { EMJ Diabet. 2020;DOI/10.3359/emidiabet/200608 } & \end{array}$

\section{INTRODUCTION}

As the COVID-19 outbreak continues to endanger global health and hamper the world economy, there are concerns and reconsiderations for medication taken by patients with cardiometabolic disorders as they are more vulnerable to COVID-19. While several articles and perspectives have dealt with the concern and safe continuation of antihypertensive drugs, there is paucity of information on calcium channel blockers (CCB). Despite the biology of calcium channel involvement in virus entry and replication, the beneficial effect of CCB is somewhat speculative and only preclinically evident. This commentary focusses on the clinical research on CCB in the context of COVID-19.

\section{THE CONCERN AND CONSENSUS ON BLOOD PRESSURE MEDICATIONS}

It has been widely observed that patients with existing cardiovascular diseases experience higher rates of complications due to COVID-19. Specifically, it has been found that patients with hypertension, diabetes, and other comorbidities are at higher risk of death from the virus. ${ }^{1,2}$ During the widespread COVID-19 pandemic, there have been worries about the potential of certain blood pressure medications such as angiotensin converting enzyme inhibitors (ACEi) and angiotensin receptor blockers (ARB). There are biological explanations for this: just like other coronaviruses, the current severe acute respiratory syndrome coronavirus 2 (SARS-CoV-2) uses the membrane-bound angiotensin converting enzyme 2 (ACE2) receptor to facilitate entry into the host cell. ${ }^{3}$ On the other hand, although ACEi and ARB do not directly affect the activity of $A C E 2$, they are known to upregulate the enzyme itself. ${ }^{4}$ The medical question posed now is whether the prescription of ACEi and ARB increases the likelihood of SARS-CoV-2 infection or if their usage increases the chance of complications from COVID-19. The good news is that there are no data to suggest that ACEi or ARB can worsen outcomes. The Centers for Disease Control and Prevention (CDC) and the European Society of Cardiology (ESC) and its council on hypertension have released position statements saying "we should not be jumping to conclusions and should not be withholding life-saving therapies from patients." More importantly, two very recent studies attest that blood pressure drugs do not increase coronavirus risk. The Wuhan Chinese study, which analysed data on the association between ACEi and ARB and outcomes in patients with hypertension hospitalised with COVID-19 infections, suggested that ACEi and ARB are 
not associated with the severity of COVID-19 or mortality in such patients. ${ }^{5}$ A study by Reynolds et al. ${ }^{6}$ found no substantial increase in the likelihood of a positive test for COVID-19 or in the risk of severity of COVID-19 among patients who tested positive in association with five common classes of antihypertensive medications. Another recent study by Meng et al. ${ }^{7}$ also supports that reninangiotensin system inhibitors (ACEi and ARB) improved the clinical outcomes of COVID-19 patients with hypertension. However, there is caution in that all these studies were based on reviewing patients' records, which does not provide evidence as strong as the results of controlled clinical trials. The good news is that several clinical trials are presently under way to test the safety and efficacy of several blood pressure medications with special reference to ACEi and ARB in COVID-19 patients.

In contrast to $A C E i / A R B$, the good news is that $\mathrm{CCB}$ do not appear to upregulate ACE2. ${ }^{8}$ Interestingly, the recent study by Reynolds et al. ${ }^{6}$ also favoured the safety and efficacy of CCB in COVID-19 patients.

\section{$\mathrm{CA}^{2+}$ AND VIRUS INFECTION: LOOKING BACK TO LEARN FROM THE PAST}

$\mathrm{Ca}^{2+}$, as well as being a 'life and death' second messenger in humans, is a predominant signal for virus entry, viral gene replication, virion maturation, and release. The prevention and therapy of virus infections are often confounded by the high mutation rates that facilitate the viral evasion of antiviral strategies. Interestingly, the alteration of host cells' $\mathrm{Ca}^{2+}$ homeostasis is one of the strategies that viruses use to modulate host cells and influence organ dysfunction in their favour. ${ }^{9}$ Once they have entered the host cell, viruses stimulate or inhibit the calcium release from internal stores that are linked to an orchestra of several calciumpermeable channels, transporters, and exchangers on organellar membranes. The ultimate change in cytosolic calcium concentration may trigger further distortion of the host cell system as well as benefit virus survival and replication.

In a study as early as in 1984, Nugent and Shanley ${ }^{10}$ reported that verapamil, the blocker of voltage gated calcium channels (VGCC) inhibited influenza $A$ virus (IAV) replication. It has been suggested that verapamil inhibits influenza virus replication by interfering with calmodulindependent intracellular activities necessary for late synthetic steps and/or virus assembly steps. Recently, it has been unravelled mechanistically that sialylated voltage-dependent $\mathrm{Ca}^{2+}$ channel binds haemagglutinin and mediates IAV entry into mammalian cells." While IAV entry was inhibited by CCB or by knockdown of voltagegated L-type calcium channel subtype (Cav1.2), this study reported that the CCB diltiazem also inhibited virus replication in vivo. While Dengue virus and West Nile virus disturb $\mathrm{Ca}^{2+}$ homeostasis to favour the viral replication turnover, cells treated with $\mathrm{Ca}^{2+}$ chelators and CCB have been shown to significantly suppress the production of viral yields. ${ }^{12,13}$ Rotavirus infection was also known to activate the endoplasmic reticulum calcium sensor stromal interaction molecule 1 and storeoperated calcium entry and thereby promote viral replication. ${ }^{14}$ On the other hand, hepatitis C virus infection was reported to increase $\mathrm{Ca}^{2+}$ uptake by mitochondria to induce apoptosis and mitochondrial dysfunction. ${ }^{15}$ CCB have also been reported to inhibit replication of several emerging viruses including Ebola virus. ${ }^{16}$

\section{PROSPECTS OF RESEARCHING ON CALCIUM CHANNEL DRUG TARGETS IN THE COVID-19 PANDEMIC}

In the context of coronavirus, the small envelope (E protein) of SARS-CoV and Middle East respiratory syndrome coronavirus (MERS-CoV) has been demonstrated to possess ion channel activity. ${ }^{17,18}$ While porcine deltacoronavirus (PDCoV) is an emerging enteropathogenic coronavirus that causes serious vomiting and diarrhoea in suckling piglets, a recent study reported that PDCoV modulates calcium influx to favour viral replication. ${ }^{19}$ In this study, treatment with $\mathrm{Ca}^{2+}$ channel blockers, particularly the L-type CCB diltiazem hydrochloride, was shown to inhibit PDCoV infection significantly. Very recently, a retrospective clinical investigation of patients with COVID-19 patients revealed that the CCB amlodipine besylate administration was associated with reduced fatality rate of patients with hypertension. ${ }^{20}$ In this study, it was also reported that $\mathrm{CCB}$ can significantly inhibit the post-entry replication events of SARS-CoV-2 in vitro. It is emphasised that, besides inhibiting 
virus replication, CCB may also function through alleviating inflammatory responses in the patients to achieve the clinical benefits in a synergistic way with their antiviral efficacy. However, it is important to note that the therapeutic mechanism of CCB against COVID-19 still awaits further investigation and randomised controlled clinical trials.

The need of the day is to develop multiple drugs against RNA viruses, such as SARSCoV-2, because these viruses generally have a high mutation rate. In fact, the prevention of and therapeutic efforts against coronavirus infections are often challenged by the high mutation rates of viral proteins. It appears that the host calcium machinery proteins required by viral entry, replication, and transmission are highly conserved, essentially immutable, and thus could be potentially targeted against virus infection. ${ }^{21}$ Currently, apart from some blockers for VGCC and the N-methyl-D-aspartate receptor, there is a paucity of other channel modulators that can be used in clinics, despite the fact that widespread research is available on a variety of calcium homeostasis machinery and ion channels. In addition to VGCC, it is time to continue to research into calcium signalling components such as store-operated channels, receptor-operated channels, and transient receptor potential ion channels in the context of their involvement in virus entry, replication, and transmission. Once this vital research is done, randomised controlled clinical trials should advance the development of specific drugs that could fight coronavirus and benefit patients.

\section{References}

1. Zheng YY et al. COVID-19 and the cardiovascular system. Nat Rev Cardiol. 2020;17:259-60. [Epub ahead of print].

2. Zhou F et al. Clinical course and risk factors for mortality of adult inpatients with COVID-19 in Wuhan, China: a retrospective cohort study. Lancet. 2020;395(10229):1054-62.

3. Zhang $\mathrm{H}$ et al. Angiotensin-converting enzyme 2 (ACE2) as a SARS-CoV-2 receptor: molecular mechanisms and potential therapeutic target. Intensive Care Med. 2020;46(4):586-90.

4. Ferrario $\mathrm{CM}$ et al. Effect of angiotensin-converting enzyme inhibition and angiotensin II receptor blockers on cardiac angiotensinconverting enzyme 2 . Circulation. 2005;111(20):2605-10.

5. Li J et al. Association of reninangiotensin system inhibitors with severity or risk of death in patients with hypertension hospitalized for coronavirus disease 2019 (COVID-19) infection in Wuhan, China. JAMA Cardiol. 2020;e201624. [Epub ahead of print].

6. Reynolds HR et al. Renin-angiotensinaldosterone system inhibitors and risk of Covid-19. N Engl J Med. 2020;NEJMoa2008975. [Epub ahead of print].

7. Meng $\mathrm{J}$ et al. Renin-angiotensin system inhibitors improve the clinical outcomes of COVID-19 patients with hypertension. Emerg Microbes Infect. 2020;9(1):757-60.

8. Centers for Disease Control (CDC) and Prevention. People at risk for serious illness from COVID-19. 2020 Available at: https://www.cdc.gov/ coronavirus/2019-ncov/specificgroups/highrisk complications. html. Last accessed 12 March, 2020.

9. Olivier M. Modulation of host cell intracellular Ca2+. Parasitol Today. 1996;12(4):145-50.

10. Nugent KM, Shanley JD. Verapami inhibits influenza A virus replication. Archives of Virology. 1984;81:163-70.

11. Fujioka $Y$ et al. A sialylated voltagedependent $\mathrm{Ca} 2+$ channel binds hemagglutinin and mediates influenza a virus entry into mammalian cells. Cell Host \& Microbe. 2018;23(6):80918.

12. Dionicio $\mathrm{CL}$ et al. Dengue virus induced changes in $\mathrm{Ca} 2+$ homeostasis in human hepatic cells that favor the viral replicative cycle. Virus Res. 2018;245:17-28.

13. Scherbik SV, Brinton MA. Virusinduced $\mathrm{Ca} 2+$ influx extends survival of West Nile Virus-infected cells. J Virol. 2010;84(17):8721-31.

14. Hyser JM et al. Activation of the endoplasmic reticulum calcium sensor STIM1 and store-operated calcium entry by rotavirus requires
NSP4 viroporin activity. J Virol. 2013;87(24):13579-88.

15. Brault $C$ et al. Hepatitis $C$ virusinduced mitochondrial dysfunctions. Viruses. 2013;5(3):954-80.

16. Johansen LM et al. A screen of approved drugs and molecular probes identifies therapeutics with anti-Ebola virus activity. Sci Transl Med. 2015;7(290):290ra89.

17. Surya $W$ et al. MERS coronavirus envelope protein has a single transmembrane domain that forms pentameric ion channels. Virus Res. 2015;201:61-6.

18. Verdia-Baguena $C$ et al. Analysis of SARS-CoV E protein ion channel activity by tuning the protein and lipid charge. Biochim Biophys Acta. 2013;1828(9):2026-31.

19. Bai $D$ et al. Porcine deltacoronavirus (PDCoV) modulates calcium influx to favor viral replication. Virology. 2020;539:38-8

20. Zhang $L$ et al. Calcium channel blocker amlodipine besylate is associated with reduced case fatality rate of COVID-19 patients with hypertension. medRxiv [Preprint]. 14 April, 2020. [cited 02.06.2020]. Preprint doi: https://doi.org/10.1101/2 020.04.08.20047134.

21. Chen $X$ et al. Host calcium channels and pumps in viral infections. Cells. 2019;9(1):94. 